\title{
Short-course therapy for diarrhea-predominant irritable bowel syndrome: understanding the mechanism, impact on gut microbiota, and safety and tolerability of rifaximin
}

This article was published in the following Dove Press journal:

Clinical and Experimental Gastroenterology

\begin{abstract}
Christopher Chang ${ }^{1,2}$
'New Mexico VA Health Care System, Division of Gastroenterology and Hepatology, Albuquerque, NM, USA; ${ }^{2}$ Department of Internal Medicine, University of New Mexico School of Medicine, Albuquerque, NM, USA
\end{abstract}

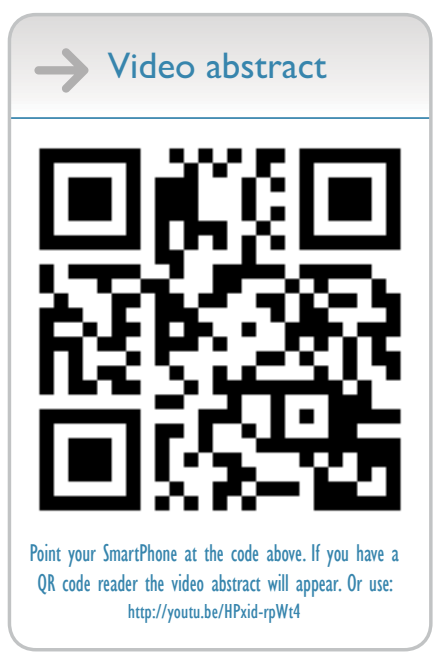

Correspondence: Christopher Chang New Mexico VA Health Care System, Division of Gastroenterology and Hepatology, I50I San Pedro Drive, SE, Albuquerque, NM 87108-5153, USA

$\mathrm{Tel}+\mid 505265$ |7| I

Fax +l 5052562803

Email CChangl@salud.unm.edu

\begin{abstract}
Irritable bowel syndrome (IBS) is a common gastrointestinal (GI) disorder characterized by abdominal pain that occurs with defecation or alterations in bowel habits. Further classification is based on the predominant bowel habit: constipation-predominant IBS, diarrheapredominant IBS (IBS-D), or mixed IBS. The pathogenesis of IBS is unclear and is considered multifactorial in nature. GI dysbiosis, thought to play a role in IBS pathophysiology, has been observed in patients with IBS. Alterations in the gut microbiota are observed in patients with small intestinal bacterial overgrowth, and overgrowth may occur in a subset of patients with IBS. The management of IBS includes therapies targeting the putative factors involved in the pathogenesis of the condition. However, many of these interventions (eg, eluxadoline and alosetron) require long-term, daily administration and have important safety considerations. Agents thought to modulate the gut microbiota (eg, antibiotics and probiotics) have shown potential benefits in clinical studies. However, conventional antibiotics (eg, neomycin) are associated with several adverse events and/or the risk of bacterial antibiotic resistance, and probiotics lack uniformity in composition and consistency of response in patients. Rifaximin, a nonsystemic antibiotic administered as a 2-week course of therapy, has been shown to be safe and efficacious for the treatment of IBS-D. Rifaximin exhibits a favorable benefit-to-harm ratio when compared with daily therapies for IBS-D (eg, alosetron and tricyclic antidepressants), and rifaximin was not associated with the emergence of bacterial antibiotic resistance. Thus, short-course therapy with rifaximin is an appropriate treatment option for IBS-D.
\end{abstract}

Keywords: antibiotic, diarrhea, dysbiosis, gastrointestinal, pain, Xifaxan

\section{Introduction}

Irritable bowel syndrome (IBS) is a chronic gastrointestinal (GI) disorder characterized by recurring abdominal pain associated with evacuation or changes in bowel habits (ie, stool form and stool frequency). ${ }^{1}$ IBS is commonly subclassified based on the predominant bowel habit (ie, constipation-predominant IBS, diarrhea-predominant IBS [IBS-D], or mixed IBS [an occurrence of both constipation and diarrhea]). A common disorder, IBS is estimated to affect $\sim 11 \%$ of adults worldwide. ${ }^{2,3}$ The pathogenesis of IBS is not completely understood, but is considered multifactorial, with the immune system, gut-brain axis, and gut microbiota thought to play roles. ${ }^{4-7}$ Indeed, increased concentrations of proinflammatory cytokines (ie, interleukin-6 and tumor necrosis factor- $\alpha$ ) have been observed in patients with IBS compared with healthy 
individuals. ${ }^{5}$ Further, interactions between the gut microbiota and central nervous system (ie, gut-brain axis) are thought to play a role in IBS pathogenesis, and the interaction is likely bidirectional. For example, psychiatric comorbidities (eg, anxiety and depression) are common in patients with IBS. ${ }^{6}$ Abdominal pain, a key component of the clinical definition of IBS, is one of the most common symptoms resulting in patients with IBS seeking consultation with a health care provider. ${ }^{8}$ The management of IBS is based on specific GI symptoms (eg, diarrhea and constipation) and the severity of those symptoms. ${ }^{1}$ However, patients with IBS may experience variations in predominant symptoms and/or IBS subtypes during their lifetime, necessitating adjustments in management approaches. ${ }^{9}$

IBS has a substantial negative effect on patients. Data suggest that patients with IBS-D experience significantly greater decreases in health-related quality of life and increased impairment of daily activities compared with healthy individuals ( $p<0.001$ for both comparisons). ${ }^{3}$ In addition, work absenteeism (ie, the percentage of work time missed related to health issues) and presenteeism (ie, the percentage of impairment experienced during work time related to health issues) are significantly more common in patients with IBS-D than in healthy individuals (absenteeism, $5.1 \%$ vs $2.9 \%$, respectively; $p=0.004$; presenteeism, $17.9 \%$ vs $11.3 \% ; p<0.001) .^{3}$

The aim of the current article was to provide an overview of the role of short-course therapy with rifaximin in the management of patients with IBS-D.

\section{Materials and methods}

A PubMed search of English language articles available through May 9, 2017, was conducted using the following keywords to identify relevant articles and studies performed in adult humans: "irritable bowel syndrome," "pathogenesis OR pathophysiology," "gut dysbiosis OR microbiota," "small intestinal bacterial overgrowth," "breath testing," "treatment," "management," "antibiotic," and "rifaximin."

\section{Role of gut microbiota in IBS}

Intestinal dysbiosis, or alterations in the quantity or composition of GI-associated microbiota, has been observed in patients with IBS. ${ }^{10-14}$ For example, results of a metaanalysis demonstrated that the expression of Lactobacillus and Bifidobacterium differed significantly between patients with IBS-D and healthy individuals ( $p=0.02$ and $p=0.001$, respectively). ${ }^{7}$ In addition, patients with IBS-D appear to have significantly lower concentrations of aerobic bacteria than that of healthy individuals $\left(1.4 \times 10^{7}\right.$ vs $8.4 \times 10^{8}$ colonyforming units $[\mathrm{CFUs}] / \mathrm{g}$ feces, respectively; $p=0.002) .{ }^{10}$

In a longitudinal study, gut microbial instability (ie, differences in microbial numbers or composition; determined using culture-independent molecular analysis [ie, PCR-denaturing gradient gel electrophoresis]) was greater in patients with IBS than in healthy individuals during a 6-month period (43\% vs $29 \%$, respectively). ${ }^{15}$ This greater instability (ie, temporal changes) in the gut microbial composition versus healthy individuals has also been specifically shown in patients with IBS-D. ${ }^{13,16,17}$ In addition, when the gut microbiota of a pooled IBS subtype population was analyzed by IBS symptom severity, patients with severe IBS (defined as IBS severity score $>300$, maximum score of 500) had decreased microbial diversity, increased Bacteroides, and a lack of Methanobacteriales compared with the gut microbiota of healthy individuals. ${ }^{18}$ To date, studies comparing the gut microbiota of patients with IBS with that of healthy individuals have been limited to demonstrating an association between dysbiosis and IBS; cause and effect remain to be elucidated. ${ }^{19}$

Small intestinal bacterial overgrowth (SIBO), characterized by quantitative and qualitative alterations in bacteria in the small intestine, is a diagnosis that may be considered in patients with nonspecific symptoms of abdominal pain, bloating, and diarrhea. ${ }^{20,21}$ Further, patients who use proton pump inhibitors (PPIs) may be at a greater risk of developing SIBO, as findings of a meta-analysis of 19 studies reported that PPIs significantly increased the risk of SIBO (odds ratio [OR], 1.7; $95 \%$ confidence interval $[\mathrm{CI}], 1.2-2.4) .{ }^{22}$ However, a study of patients undergoing upper GI tract endoscopy $(n=897)$ showed no association between PPI use and SIBO. ${ }^{23}$ In 2017, the North American Consensus group on hydrogen- and methane-based breath testing proposed a bacterial concentration of $>10^{3} \mathrm{CFU} / \mathrm{mL}$ following aspiration of small intestine fluid and subsequent culture as meeting the threshold for a diagnosis of SIBO. ${ }^{24}$ In one study, more patients with IBS ( $43 \%$ ) achieved a positive culture threshold of $\geq 5 \times 10^{3} \mathrm{CFU} /$ $\mathrm{mL}$ compared with healthy individuals $(12 \% ; p=0.002){ }^{25}$ Conversely, a retrospective study of patients with IBS failed to show an association between IBS and SIBO (OR, 0.2; 95\% CI, 0.1-0.7). ${ }^{26}$ However, obtaining small intestinal aspirate samples for culture is an invasive procedure, and differences in findings may be related to inconsistencies in sample collection, in vitro growth, and the potential for contamination (ie, bacteria from outside the small intestine). ${ }^{24,27}$

Although criteria for diagnosing IBS are based on patient symptoms, breath testing - a method that measures the production of gases (eg, hydrogen and methane) that 
result from bacterial fermentation of orally administered but unabsorbed carbohydrates (eg, glucose, lactose, and lactulose) in the GI tract - may be used for various reasons, such as to determine the presence of SIBO or carbohydrate malabsorption. ${ }^{1,24,28} \mathrm{~A}$ meta-analysis of 11 studies found that positive breath tests occurred more frequently in patients with IBS $(\mathrm{n}=1076)$ than in healthy individuals $(\mathrm{n}=509$; OR, $4.5 ; 95 \% \mathrm{CI}, 1.7-11.8 ; p=0.003) .{ }^{29} \mathrm{~A}$ study published after that meta-analysis was conducted reported that $23.7 \%$ of patients with IBS had positive breath test results compared with $2.7 \%$ of healthy individuals $(p=0.008) .{ }^{30}$ That study also reported that, based on breath test results, SIBO was more prevalent in patients with IBS-D (37.0\%) than in patients with other IBS subtypes $(12.5 \% ; p=0.02) .{ }^{30}$ However, other studies have failed to demonstrate an association between SIBO (based on breath testing) and IBS. ${ }^{31,32}$ Thus, bacterial culture and breath-testing data appear to suggest that at least a subset of patients with IBS may have alterations in their gut microbiota. These findings, which remain to be confirmed by larger, well-designed studies, suggest that empiric treatment of patients with IBS thought to have comorbid SIBO may be warranted..$^{9,29,33}$

Given the multifactorial nature of IBS, various types of therapeutic options are prescribed to help manage the symptoms of IBS-D (Table 1). ${ }^{1}$ To manage individual symptoms of IBS, most of these agents must be administered daily, either long term or as needed (eg, antispasmodics or peppermint oil for abdominal pain), or administered off-label to manage global IBS symptoms alongside psychiatric comorbidities (eg, tricyclic antidepressants or selective serotonin reuptake inhibitors may improve coexisting anxiety or depression, as well as decrease visceral pain). ${ }^{9}$

Some agents (eg, antibiotics and probiotics) administered for the treatment of IBS are thought to modulate the gut microbiota, possibly by correcting dysbiosis. ${ }^{1,12-14}$ Patients with IBS treated with short-course conventional (traditional) antibiotics (ie, ciprofloxacin, doxycycline, neomycin, and metronidazole) have had improvements in IBS symptoms, such as diarrhea $(p<0.05)$ and abdominal pain $(p<0.001) .{ }^{34}$ Results of a double-blind, randomized, placebo-controlled study demonstrated that patients with IBS receiving neomycin had a significantly greater decrease in the IBS composite symptom score (ie, abdominal pain, diarrhea, and constipation) compared with placebo ( $35.0 \%$ vs $11.4 \%$, respectively; $p<0.05)$; neomycin was more likely to result in a clinical response (ie, $\geq 50 \%$ improvement from baseline in composite symptom score) than placebo ( $44 \%$ vs $23 \%$; OR, 4.3 ; CI, $1.0-6.3 ; p<0.05) .{ }^{35}$ Further, a retrospective chart review of patients with IBS and the presence of methane by lactulose
Table I Therapies for the management of patients with IBS-D

\begin{tabular}{lll}
\hline Therapeutic class & Example of therapy & Dosing \\
\hline Antibiotics & Rifaximin & $\begin{array}{l}550 \mathrm{mg} \text { tid for } \\
14 \text { days }\end{array}$ \\
Antispasmodics & Dicyclomine & $10-20 \mathrm{mg}$ qd-qid \\
& Hyoscyamine & $0.125-0.25 \mathrm{mg}$ every \\
& & 4 hours as needed \\
Bile acid sequestrants & Cholestyramine & $9 \mathrm{~g} \mathrm{bid-tid}$ \\
& Colesevelam & $625 \mathrm{mg}$ qd-bid \\
& Colestipol & $2 \mathrm{~g} \mathrm{qd-bid}$ \\
Diet & Low gluten/gluten-free & Daily \\
& Low FODMAP & Daily \\
Mixed opioid agonist/ & Eluxadoline & $100 \mathrm{mg}$ bid \\
antagonist & & \\
Opioid agonists & Loperamide & $2-4 \mathrm{mg}$ as needed; \\
& & titrated to $16 \mathrm{mg} / \mathrm{d}$ \\
Peppermint oil & Enteric-coated capsules & $250-750 \mathrm{mg}$ bid-tid \\
Probiotics & Multiple products & Daily \\
Selective serotonin & Citalopram & $10-40 \mathrm{mg}$ qd \\
reuptake inhibitors & Paroxetine & $10-40 \mathrm{mg}$ qd \\
& Sertraline & $25-100 \mathrm{mg}$ qd \\
Tricyclic antidepressants & Amitriptyline & $10-50 \mathrm{mg}$ qhs \\
& Desipramine & $25-100 \mathrm{mg}$ qhs \\
$5-\mathrm{HT}{ }_{3}$ antagonists & Alosetron & $0.5-1 \mathrm{mg}$ bid \\
& Ondansetron & (women only) \\
& & $4-8 \mathrm{mg}$ tid \\
\hline Note: & &
\end{tabular}

Note: ${ }^{2}$ Not indicated for use in patients with IBS. Adapted from Gastroenterology, I50(6), Lacy BE, Mearin F, Chang L, et al, Bowel disorders, I393-I407, Copyright (2016), with permission from Elsevier.'

Abbreviations: 5- $\mathrm{HT}_{3}$, serotonin; bid, twice daily; FODMAP, fermentable oligosaccharides, disaccharides, monosaccharides, and polyols; IBS, irritable bowel syndrome; IBS-D, diarrhea-predominant irritable bowel syndrome; qd, once daily; qhs, nightly at bedtime; qid, four times daily; tid, three times daily.

breath testing showed that neomycin was associated with clinical response in $63 \%$ of 8 patients..$^{36}$ However, the use of these conventional antibiotics is limited by the risk for Clostridium difficile infection, the potential for the emergence of bacterial antibiotic resistance, and the risk of systemic adverse events (AEs) such as ototoxicity (ie, neomycin). ${ }^{37-39}$ These agents should be avoided in routine clinical practice for the treatment of IBS. Further, some patients with IBS may not respond to retreatment with conventional antibiotics when IBS symptoms recur. ${ }^{38,40}$

In general, probiotics, typically administered daily, may improve global symptoms of IBS, along with bloating and flatulence. ${ }^{9}$ Interestingly, data for a subset of studies in a 2016 meta-analysis ( 13 trials; $\mathrm{n}=889$ patients) indicated that probiotics do not improve abdominal pain, a key individual symptom in IBS, versus placebo. ${ }^{41}$ Furthermore, there is a lack of consistency of response in patients (Table 2), ${ }^{41-46}$ likely because probiotic formulations vary in composition (single or multiple species and strains of microbes) and dose and duration and also because the trials conducted have often been considered substandard. ${ }^{9,41}$ Moreover, results with one strain cannot be extrapolated to another strain from the 
Table 2 Summary of meta-analyses of randomized, controlled studies of antibiotics and probiotics in patients with IBS

\begin{tabular}{|c|c|c|c|}
\hline Publication & Patient inclusion criteria & $\begin{array}{l}\text { RCTs in } \\
\text { meta-analysis, } n\end{array}$ & Outcomes \\
\hline \multicolumn{4}{|l|}{ Antibiotics } \\
\hline Li et $\mathrm{al}^{42}$ & $\begin{array}{l}\text { - Adults aged } \geq 18 \text { years } \\
\text { - IBS diagnosis }\end{array}$ & 4 (n=1803 pts) & $\begin{array}{l}\text { - Remission of overall IBS symptoms, rifaximin vs placebo } \\
\text { - End of treatment: OR, I.2 ( } 95 \% \mathrm{Cl}, \mathrm{I} . \mathrm{I}-\mathrm{I} .3 ; p=0.0008) \\
\text { - End of follow-up: OR, I.4 ( } 95 \% \mathrm{Cl}, \mathrm{I} .2-\mathrm{I} .6 ; p<0.000 \mathrm{I}) \\
\text { - Adverse events, rifaximin vs placebo } \\
\text { - Abdominal pain ( } \mathrm{n}=3 \text { studies): OR, I.0I }(95 \% \mathrm{Cl}, 0.98-\mathrm{I} .03 ; p=0.6) \\
\text { - Nausea ( } \mathrm{n}=3 \text { studies): OR, I.0 }(95 \% \mathrm{Cl}, 0.98-1.02 ; p=0.8) \\
\text { - Vomiting ( } \mathrm{n}=3 \text { studies): OR, } 0.99(95 \% \mathrm{Cl}, 0.98-1.01 ; p=0.3) \\
\text { - Headache ( } \mathrm{n}=3 \text { studies): OR, I.0I }(95 \% \mathrm{Cl}, 0.98-1.03 ; p=0.6)\end{array}$ \\
\hline $\begin{array}{l}\text { Menees } \\
\text { et } \mathrm{al}^{43}\end{array}$ & $\begin{array}{l}\text { - IBS diagnosis (according } \\
\text { to Manning, Kruis, Rome I, } \\
\text { Rome II, Rome III criteria) }\end{array}$ & 5 (n=1803 pts) & $\begin{array}{l}\text { - Improvement of global IBS symptoms, rifaximin vs placebo } \\
-42.2 \% \text { vs } 32.4 \% \text {; OR, I.6 ( } 95 \% \mathrm{Cl}, \mathrm{I} .2-2.0 ; p<0.00 \mathrm{I}) \\
\text { - Improvement in bloating } \text {, rifaximin vs placebo ( } \mathrm{n}=4 \text { studies }) \\
-41.6 \% \text { vs } 31.7 \% \text {; OR, I.6 ( } 95 \% \mathrm{Cl}, \mathrm{I} .2-2.0 ; p<0.00 \mathrm{I})\end{array}$ \\
\hline \multicolumn{4}{|l|}{ Probiotics } \\
\hline$\overline{Z \text { Zhang et } \mathrm{al}^{41}}$ & $\begin{array}{l}\text { - IBS diagnosis (Rome III } \\
\text { criteria) } \\
\text { - Treatment } \geq 7 \text { days }\end{array}$ & Overall: 21 & $\begin{array}{l}\text { - Overall symptom response }(\mathrm{n}=16 \text { studies; } \mathrm{n}=1275 \mathrm{pts}) \\
\text { - Probiotics vs placebo: } 53.3 \% \text { vs } 27.7 \%(\mathrm{RR}, \mathrm{I} .8 ; 95 \% \mathrm{Cl}, \mathrm{I} .3-2.6) \\
\text { - Abdominal pain response }(\mathrm{n}=13 \text { studies; } \mathrm{n}=889) \\
\text { - Probiotics vs placebo: } \mathrm{SMD},-0.3(95 \% \mathrm{Cl},-0.6 \text { to } 0.1) \\
\text { - Bloating ( } \mathrm{n}=\mathrm{I} 3 \text { studies; } \mathrm{n}=890 \mathrm{pts}) \\
\text { - Probiotics vs placebo: } \mathrm{SMD},-0.2(95 \% \mathrm{Cl},-0.5 \text { to } 0.1) \\
\text { - QOL }(\mathrm{n}=9 \text { studies; } \mathrm{n}=629 \mathrm{pts}) \\
\text { - Probiotics vs placebo: } \mathrm{SMD}=0.3(95 \% \mathrm{Cl}, 0 . \mathrm{I}-0.5)\end{array}$ \\
\hline $\begin{array}{l}\text { Didari } \\
\text { et } \mathrm{al}^{44, \mathrm{~b}}\end{array}$ & $\begin{array}{l}\text { - IBS diagnosis (Rome II and } \\
\text { III criteria, and International } \\
\text { Classification of Health } \\
\text { Problems in Primary Care } \\
\text { and World Organization of } \\
\text { Family Doctors) }\end{array}$ & Overall: I5 (n=1793 pts) & $\begin{array}{l}\text { - Global symptom response ( } \mathrm{n}=2 \text { studies) } \\
\text { - Probiotics vs placebo: } \mathrm{RR}, 2.4 \text { ( } 95 \% \mathrm{Cl}, \mathrm{I} . \mathrm{I}-5.2 ; p=0.02) \\
\text { - Adequate general symptoms improvement ( } \mathrm{n}=6 \text { studies) } \\
\text { - Probiotics vs placebo: } \mathrm{RR}, 2 . \mathrm{I}(95 \% \mathrm{Cl}, \mathrm{I} . \mathrm{I}-4.3 ; p=0.03) \\
\text { - Abdominal pain response }(\mathrm{n}=2 \text { studies) } \\
\text { - Probiotics vs placebo: } \mathrm{RR}, 2.0(95 \% \mathrm{Cl}, \mathrm{I} . \mathrm{I}-3.4 ; p=0.0 \mathrm{I})\end{array}$ \\
\hline Ford et $\mathrm{al}^{45}$ & $\begin{array}{l}\text { - } \text { Adults aged }>16 \text { years } \text { with } \\
\text { IBS } \\
\text { - Treatment } \geq 7 \text { days } \\
\text { - } \text { Follow-up } \geq 7 \text { days }\end{array}$ & $\begin{array}{l}\text { - Overall: } 35 \\
\text { - Combination } \\
\text { probiotics: } 19 \\
\text { - Lactobacillus: } 8 \\
\text { - Bifidobacterium: } 3 \\
\text { - Escherichia: } 2 \\
\text { - Bifidobacterium or } \\
\text { Lactobacillus: I } \\
\text { - Saccharomyces: I } \\
\text { - Streptococcus: I }\end{array}$ & 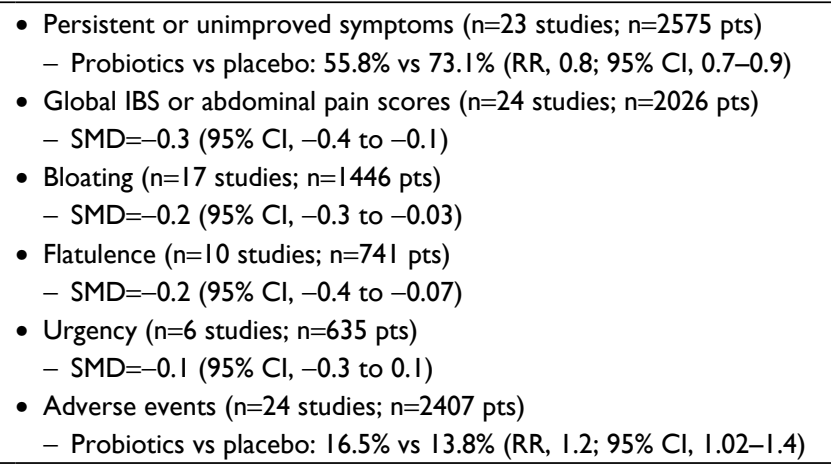 \\
\hline Moayyedi & - Adults aged $>16$ y with IBS & - Overall: 18 & - Overall symptom response ( $\mathrm{n}=15$ studies; $\mathrm{n}=135 \mathrm{I}$ pts) \\
\hline et $\mathrm{al}^{46}$ & $\begin{array}{l}\text { - Treatment } \geq 7 \text { days } \\
\text { - Follow-up } \geq 7 \text { days }\end{array}$ & $\begin{array}{l}\text { - Combination } \\
\text { probiotics: } 9 \\
\text { - Lactobacillus: } 6 \\
\text { - Bifidobacterium: } 3 \\
\text { - Lactobacillus and } \\
\text { Bifidobacterium: I } \\
\text { - Streptococcus: I }\end{array}$ & $\begin{array}{l}\text { - Probiotics vs placebo: } \mathrm{SMD}=-0.3(95 \% \mathrm{Cl},-0.6 \text { to }-0.07) \\
\text { - Persistent or unimproved overall symptoms }(\mathrm{n}=10 \text { studies; } \mathrm{n}=918 \mathrm{pts}) \\
\text { - Probiotics vs placebo: } \mathrm{RR}, 0.7(95 \% \mathrm{Cl}, 0.6-0.9) \\
\text { - Abdominal pain response }(\mathrm{n}=9 \text { studies; } \mathrm{n}=834 \mathrm{pts}) \\
\text { - Probiotics vs placebo: } \mathrm{SMD}=-0.5(95 \% \mathrm{Cl},-0.9 \text { to }-0.1 ; p=0.02) \\
\text { - Bloating ( } \mathrm{n}=7 \text { studies; } \mathrm{n}=682 \mathrm{pts}) \\
\text { - Probiotics vs placebo: } \mathrm{SMD}=-0.5(95 \% \mathrm{Cl},-\mathrm{I} . \mathrm{I} \text { to } 0.02 ; p=0.06) \\
\text { - Flatulence ( } \mathrm{n}=6 \text { studies; } \mathrm{n}=566 \mathrm{pts}) \\
\text { - Probiotics vs placebo: } \mathrm{SMD}=-0.2(95 \% \mathrm{Cl},-0.4 \text { to }-0.01 ; p=0.04) \\
\text { - Urgency ( } \mathrm{n}=3 \text { studies; } \mathrm{n}=394 \mathrm{pts}) \\
\text { - Probiotics vs placebo: } \mathrm{SMD}=-0.1(95 \% \mathrm{Cl},-0.3 \text { to } 0.1 ; p=0.5) \\
\text { - Adverse events ( } \mathrm{n}=3 \text { studies; } \mathrm{n}=407 \mathrm{pts}) \\
\text { - Probiotics vs placebo: } \mathrm{RR}, 0.9(95 \% \mathrm{Cl}, 0.6-1.4)\end{array}$ \\
\hline
\end{tabular}

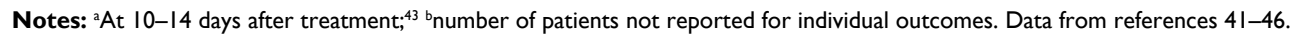

Abbreviations: Cl, confidence interval; IBS, irritable bowel syndrome; OR, odds ratio; QOL, quality of life; pts, patients; RCT, randomized controlled trial; RR, relative risk; SMD, standard mean difference. 
same species. ${ }^{9}$ However, an open-label, prospective study published in 2018 demonstrated that 30-day treatment with a commercially available probiotic significantly improved bowel function satisfaction in patients with IBS-D $(n=11)$ compared with patients with non-IBS-D $(n=15)$ on days 30 and 60 ( $p=0.05$ and 0.04 , respectively) ${ }^{47}$ Further, following 30-day probiotic treatment, patients with IBS and concomitant SIBO experienced a significantly greater decrease from baseline in the severity of IBS symptoms compared with patients with IBS without SIBO at day 60 (71.3\% vs $10.6 \%$, respectively; $p=0.02) .{ }^{47}$ Given the potential benefit in targeting the gut microbiota, a nonsystemic antibiotic has been investigated to prevent the need for long-term daily therapy and minimize possible AEs.

\section{Rifaximin for the treatment of IBS}

Rifaximin, a nonsystemic antibiotic indicated in the USA for the treatment of adults with IBS-D, is administered as a 2-week course of therapy. ${ }^{48}$ Rifaximin is also indicated as a daily therapy for the reduction of risk of overt hepatic encephalopathy in adults. ${ }^{48}$ The mechanism of action of rifaximin, including in IBS, is not fully understood. However, its activities for the treatment of various GI-related conditions are thought to involve modulation of the gut microbiota (eg, SIBO eradication), ${ }^{49}$ immune components (eg, decreased proinflammatory cytokine concentrations), ${ }^{50}$ and the gut-brain axis (eg, cognitive improvement observed in patients with cirrhosis). ${ }^{51}$ Rifaximin has been evaluated in three phase III IBS trials, ${ }^{52,53}$ and findings of randomized, placebo-controlled trials of rifaximin have been summarized in several meta-analyses (Table 2). ${ }^{42,43}$ In two phase III, identically designed, randomized, double-blind, placebo-controlled studies, significantly more patients receiving rifaximin 550 mg three times daily (tid) for 2 weeks achieved adequate relief from global IBS symptoms for $\geq 2$ of the first 4 weeks posttreatment compared with placebo (pooled, $40.7 \%$ vs $31.7 \%$, respectively; $p<0.001) .{ }^{52}$ The durability of response to rifaximin was maintained for at least 3 months posttreatment and differed significantly from placebo $(p<0.001) .{ }^{52}$ Rifaximin had a safety and tolerability profile comparable with that of placebo, with headache (6.1\% vs $6.6 \%)$, upper respiratory tract infection $(5.6 \%$ vs $6.2 \%)$, and abdominal pain $(4.6 \%$ vs $5.5 \%)$ being the most commonly reported AEs. ${ }^{52}$ In addition, no patients reported C. difficile-associated diarrhea or ischemic colitis during these two trials. ${ }^{52}$

In an earlier randomized, double-blind, placebo-controlled, investigator-initiated study that evaluated rifaximin $400 \mathrm{mg}$ tid for 10 days in patients with IBS (a lower dose of rifaximin given for a shorter duration than the indicated dosing), rifaximin significantly improved global symptoms from baseline compared with placebo after 10 weeks of treatmentfree follow-up (36.4\% vs $21.0 \%$, respectively; $p=0.02) .{ }^{54}$ Based on the two phase III trials, ${ }^{52}$ the investigator-initiated trial, ${ }^{54}$ and two additional trials (one phase II $^{55}$ and one singlecenter $^{56}$ ), the 2014 American College of Gastroenterology concluded that rifaximin was effective for the reduction of total symptoms of IBS and bloating in patients with IBS-D. ${ }^{9}$ In that same year, the American Gastroenterological Association provided a conditional recommendation for rifaximin for the treatment of IBS-D. ${ }^{57}$

The efficacy findings of the two pivotal studies ${ }^{52}$ of rifaximin were comparable with the data reported during a phase III repeat treatment study published in $2016 .{ }^{53}$ In that randomized, double-blind, placebo-controlled repeat treatment trial, patients with IBS-D who responded to a 2-week course of open-label rifaximin ( $\geq 30 \%$ decrease from baseline in mean weekly pain score and $\geq 50 \%$ decrease from baseline in the frequency of mushy/watery stools during $\geq 2$ of the first 4 weeks posttreatment) and experienced symptom recurrence $(<30 \%$ decrease in weekly mean abdominal pain score or $<50 \%$ decrease from baseline in the frequency of mushy/watery stools) for $\geq 3$ weeks during a rolling 4 -week consecutive period of the 18 -week treatment-free observation phase were eligible for repeat treatment (Figure 1). ${ }^{53}$ Patients were randomly assigned to receive two repeat courses of rifaximin $550 \mathrm{mg}$ or placebo tid for 14 days; the two double-blind courses were separated by 10 weeks. ${ }^{53}$ In the open-label treatment-free observation phase, $35.6 \%$ of 1074 patients with IBS-D who responded to a 2-week course of rifaximin reported no recurrence of symptoms (ie, up to 22 weeks posttreatment) and were not further evaluated. ${ }^{53}$ A significantly greater percentage of patients with recurrence who received the first repeat treatment course in the double-blind phase achieved the primary efficacy outcome of combined weekly response for abdominal pain and stool consistency during $\geq 2$ of the first 4 weeks after repeat treatment versus placebo $(38.1 \%$ vs $31.5 \%$, respectively; $p=0.03) .{ }^{53}$ Interestingly, patients who entered the double-blind repeat treatment phase (ie, after responding to a 2-week course of open-label rifaximin and subsequently experiencing recurrence) had significantly lower severity in individual symptom scores at double-blind baseline (prior to starting double-blind treatment) than what had been reported at the start of open-label treatment ( $p<0.001$, for all comparisons), suggesting residual benefit from the first course of rifaximin therapy. ${ }^{53}$ 


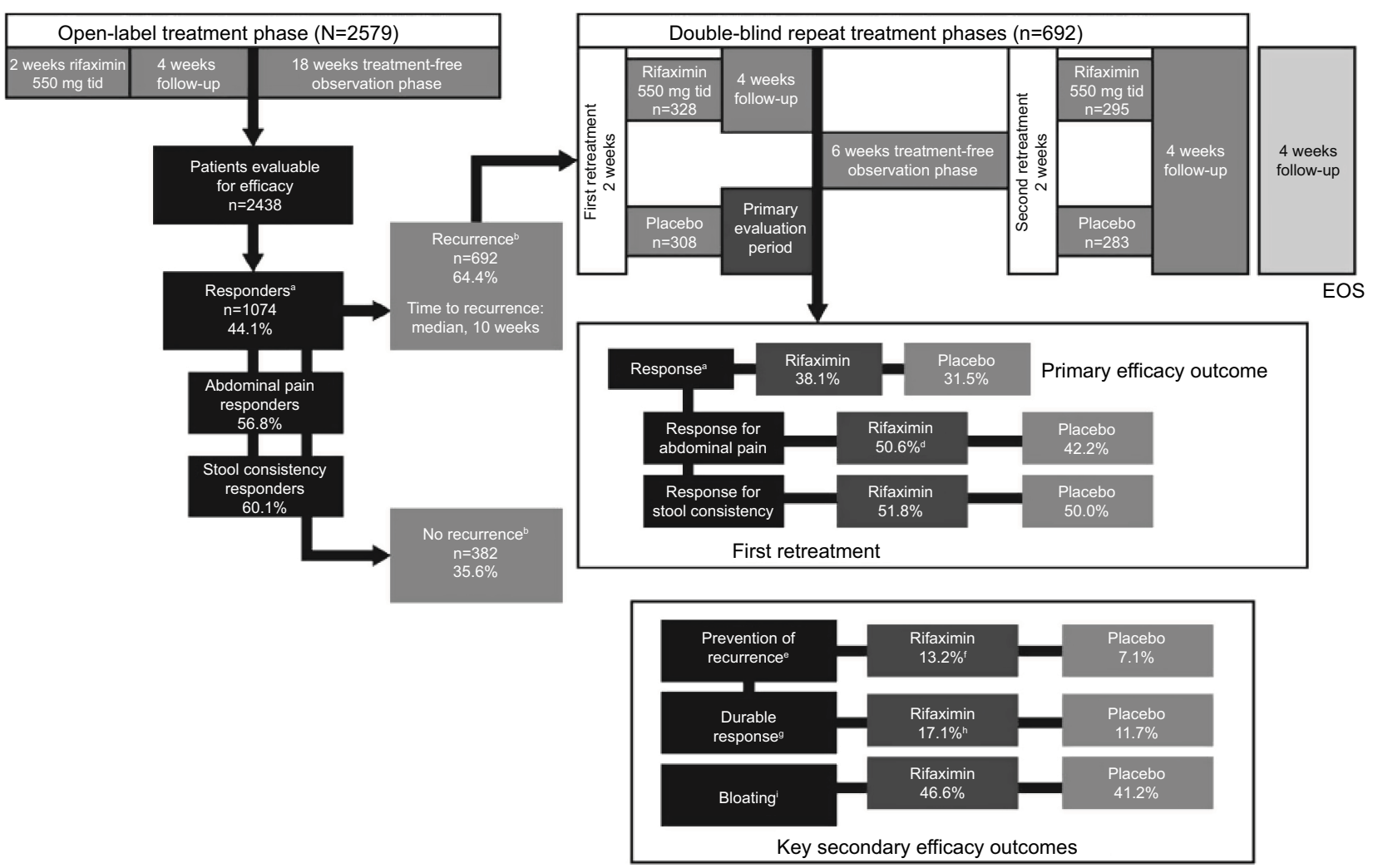

Figure I Repeat treatment trial study design and efficacy outcomes. ${ }^{53}$

Notes: aSimultaneously meeting weekly response criteria for abdominal pain ( $\geq 30 \%$ decrease from baseline in mean weekly pain score) and stool consistency ( $\geq 50 \%$ decrease from baseline in number of days/week with Bristol Stool Scale type 6 or 7 stool) during $\geq 2$ of the first 4 weeks posttreatment; bin patients with response to open-label rifaximin 4 weeks posttreatment, during the 18-week treatment-free observation phase; $c p=0.03$; ${ }^{d} p=0.02$; ${ }^{e}$ Defined as the percentage of patients with response through the end of the first 6-week treatment-free observation phase and through the end of the second repeat treatment phase; ${ }^{f} p=0.007 ;{ }^{8} D e f i n e d$ as adequate relief in both abdominal pain and stool consistency throughout the first double-blind repeat phase (through the 6-week treatment-free observation phase); ${ }^{h} p=0.04$; 'percentage of patients with improvement from baseline $\geq I$ point in weekly average bloating score for $\geq 2$ of 4 weeks of primary evaluation period.

Abbreviations: EOS, end of study; tid, three times daily.

Rifaximin has been available for the last 30 years (in Italy since 1987 and in the USA since 2004), is currently marketed in more than 47 countries, and has a well-established safety and tolerability profile. ${ }^{58-60} \mathrm{~A}$ pooled safety analysis that included data from three randomized controlled studies (ie, one phase IIb and two phase III studies) of rifaximin for the treatment of nonconstipation IBS showed that rifaximin had a safety profile comparable with that of placebo (Table 3). ${ }^{61}$ Furthermore, the repeat (up to three courses) treatment trial did not identify any new safety concerns ${ }^{53}$ One patient in the repeat treatment trial developed $C$. difficile colitis 37 days after receiving 2-week repeat rifaximin treatment; however, this patient, who had a history of $C$. difficile infection, received a 10-day course of cefdinir as a treatment for a urinary tract infection immediately preceding the development of $C$. difficile colitis. ${ }^{53}$

In a separate analysis, rifaximin was determined to be a safe and well-tolerated treatment for patients with IBS$\mathrm{D}$, with a favorable "benefit-to-harm" ratio, particularly in comparison with therapies that are administered daily, long term for IBS (eg, alosetron and tricyclic antidepressants; Table 4). ${ }^{62,63}$ Although rifaximin is administered as a 2-week course of therapy in IBS-D, rifaximin has a well-established safety and tolerability profile as daily, long-term administration of $550 \mathrm{mg}$ bid for the maintenance of remission of overt hepatic encephalopathy in patients with cirrhosis (ie, $\geq 2$ years; 510.5 person-years of exposure). ${ }^{64}$

\section{Considerations for daily, long-term versus short-course therapy}

The management of IBS includes both long-term and shortterm management strategies to help control symptoms. Most patients with IBS (89.6\%) reported that they consider diet to cause and/or exacerbate GI symptoms, and most (91.9\%) reported modifying their diet to try and decrease symptoms of IBS. ${ }^{65}$ However, some specialized diets (eg, low fermentable oligosaccharides, disaccharides, monosaccharides, and polyols [FODMAP] and low gluten/gluten-free) may be difficult 
Table 3 Summary of safety of rifaximin $550 \mathrm{mg}$ with nonconstipation IBS ${ }^{\mathrm{a}}$

\begin{tabular}{|c|c|c|}
\hline \multirow[t]{2}{*}{ Patients with AEs } & \multicolumn{2}{|l|}{ Patients, n (\%) } \\
\hline & $\begin{array}{l}\text { Rifaximin } 550 \mathrm{mg} \\
(\mathrm{n}=1008)\end{array}$ & $\begin{array}{l}\text { Placebo } \\
(n=829)\end{array}$ \\
\hline Any $\mathrm{AE}$ & $529(52.5)$ & $436(52.6)$ \\
\hline \multicolumn{3}{|l|}{ Most common AEs ${ }^{b}$} \\
\hline Headache & $55(5.5)$ & $51(6.2)$ \\
\hline Upper respiratory tract infection & $45(4.5)$ & $47(5.7)$ \\
\hline Nausea & $4 \mid(4.1)$ & $31(3.7)$ \\
\hline Abdominal pain & $40(4.0)$ & $39(4.7)$ \\
\hline Diarrhea & $35(3.5)$ & $26(3.1)$ \\
\hline Urinary tract infection & $32(3.2)$ & $18(2.2)$ \\
\hline Nasopharyngitis & $26(2.6)$ & $39(4.7)$ \\
\hline Sinusitis & $23(2.3)$ & $23(2.8)$ \\
\hline Vomiting & $20(2.0)$ & $12(1.4)$ \\
\hline Back pain & $20(2.0)$ & $19(2.3)$ \\
\hline Drug-related AEs & $124(12.3)$ & $89(10.7)$ \\
\hline \multicolumn{3}{|l|}{ Serious AEs } \\
\hline Any serious $A E$ & $15(1.5)$ & $18(2.2)$ \\
\hline Drug-related serious AEs & $\mathrm{I}(0.1)$ & $2(0.2)$ \\
\hline Discontinuations related to $\mathrm{AEs}$ & $19(1.9)$ & $14(1.7)$ \\
\hline
\end{tabular}

Notes: aPooled data from patients receiving rifaximin $550 \mathrm{mg}$ bid for 2 or 4 weeks in a phase Ilb clinical study or rifaximin $550 \mathrm{mg}$ tid for 2 weeks in two phase III studies; ${ }^{b} A E s$ reported in $\geq 2 \%$ of patients in either group. Adapted from Schoenfeld $P$, Pimentel M, Chang L, et al. Safety and tolerability of rifaximin for the treatment of irritable bowel syndrome without constipation: a pooled analysis of randomised, double-blind, placebo-controlled trials. Aliment Pharmacol Ther. 2014;39(10): II6I1168. With permission from John Wiley and Sons. ${ }^{61}$

Abbreviations: $A E$, adverse event; bid, twice daily; IBS, irritable bowel syndrome; tid, three times daily.

Table 4 Benefit to harm evaluation of treatment for patients with IBS-D ${ }^{\mathrm{a}, \mathrm{b}}$

\begin{tabular}{llll}
\hline Treatment & $\begin{array}{l}\text { Number } \\
\text { needed } \\
\text { to treat }\end{array}$ & $\begin{array}{l}\text { Number } \\
\text { needed } \\
\text { to harm }\end{array}$ & $\begin{array}{l}\text { Number of patients } \\
\text { benefiting for one } \\
\text { patient harmed }\end{array}$ \\
\hline Alosetron & 7.5 & 19.4 & 2.6 \\
Tricyclic antidepressants & 8 & 18.3 & 2.3 \\
Rifaximin & 10.6 & 8971 & 846 \\
\hline
\end{tabular}

Notes: aEluxadoline data were not available at time study was conducted; bbased on discontinuation data due to an adverse event; 'ratio of the number needed to treat to the number needed to harm. Adapted from Am J Med, I25(4), Shah E, Kim S, Chong K, Lembo A, Pimentel M, Evaluation of harm in the pharmacotherapy of irritable bowel syndrome, 38I-393, Copyright (20I2), with permission from Elsevier, ${ }^{62}$ with additional data from Shah E, Pimentel M. Aliment Pharmacol Ther. 2014;39(9):973-983.63 Abbreviation: IBS-D, diarrhea-predominant irritable bowel syndrome.

for patients to maintain long term. ${ }^{9}$ Specific diets, including ones low in FODMAPs, are efficacious in improving symptoms of IBS; however, patients are advised to methodically and systematically reintroduce components of the previously restricted high FODMAP diet to determine the level of food restriction that is needed to maintain symptom control. ${ }^{66}$

A retrospective database analysis of any prescription type reported for patients receiving services from a large US-managed care organization (398,025 patients; 569,095 prescriptions) indicated that the predicted probability of nonadherence to treatment was greater for chronic (ongoing; long-term) versus short-course (ie, acute) therapy (34\% vs $17 \%$, respectively) ${ }^{67}$ Further, questionnaire data from patients with GI disorders, including IBS, indicated that selfreported adherence to treatment was inversely correlated to patient concerns regarding harm associated with treatment $(r=-0.24 ; p<0.001){ }^{68}$ Adherence to treatment is important, given that many of the options available for patients with IBS-D (Table 1) are ongoing, long-term (chronically administered) therapies ${ }^{1}$ and may also be associated with less desirable attributes and adverse effects. ${ }^{69}$

The benefit-to-risk profile of pharmacologic therapies for patients with IBS is an important consideration in guiding therapy. Certain pharmacologic agents (eg, eluxadoline and alosetron) used in the long term and indicated for the treatment of patients with IBS-D require daily administration. ${ }^{70,71}$ Eluxadoline treatment effects begin to diminish within 2-3 weeks after drug discontinuation. ${ }^{72,73}$ Alosetron treatment effects diminish rapidly (within 1 week to 1 month) after drug discontinuation. ${ }^{74-76}$ Further, eluxadoline and alosetron have been associated with the occurrence of infrequent but serious AEs. ${ }^{71,73,77}$ It is important to note that, in response to safety concerns, such as the potential for the occurrence of the rare but serious AEs of ischemic colitis and constipation complications, alosetron is available in the USA under a risk evaluation and mitigation strategy program. However, an examination of 9 years of postmarketing data collected after inception of the risk management program showed that the incidence of ischemic colitis remained infrequent and stable, while complications of constipation decreased. ${ }^{77}$

In March 2017, the US Food and Drug Administration issued a safety communication warning that eluxadoline should not be administered to patients without a gallbladder because of the risk of developing serious pancreatitis that could result in hospitalization or mortality. ${ }^{78}$ From May 2015 through February 2017, the agency received 120 reports of serious cases of pancreatitis or mortality. Among the 68 patients with available gallbladder status, $56 \mathrm{did}$ not have a gallbladder and received the indicated dosage of eluxadoline $;{ }^{78}$ hence, eluxadoline is contraindicated in patients without a gallbladder. ${ }^{70}$ Furthermore, the eluxadoline prescribing information warns of a risk of sphincter of Oddi spasm, resulting in pancreatitis or hepatic enzyme elevation associated with acute abdominal pain. ${ }^{70} \mathrm{~A} 2017$ pooled safety data analysis of one phase II and two phase III clinical studies reported that while uncommon, pancreatitis was the most common serious $\mathrm{AE}$ reported with eluxadoline; fortunately, pancreatitis resolved in all affected patients. ${ }^{79}$

Daily probiotics are commonly considered for managing GI conditions, but as noted previously, the most appropriate 
strain(s) to be used in managing symptoms of IBS, and at which dose, are currently unknown. ${ }^{9,80}$ Furthermore, evidence supporting the effectiveness of probiotics for the management of IBS symptoms is less robust than that for the treatment of other GI-related conditions (eg, pouchitis). ${ }^{81}$

Given the inherent disadvantages of therapies that require long-term administration, several short-course or as-needed therapies are administered for the management of IBS. Antispasmodics (eg, dicyclomine) are efficacious for short-term relief of IBS symptoms, but results of a pooled analysis of 15 clinical studies indicated an increased risk of AEs versus placebo (relative risk, 1.6; 95\% CI, 1.1-2.4). ${ }^{9}$ Antispasmodics may in fact be administered as a long-term therapy, but are also administered as needed to manage individual symptoms. Although data on efficacy and safety in IBS are limited, fecal microbial transplant as short-course or as-needed therapy is currently considered an investigational treatment and is a complex procedure involving a donor and a patient. ${ }^{82}$

The efficacy of the nonsystemic agent rifaximin is favorable for the treatment of IBS-D compared with placebo in clinical studies, ${ }^{52,53}$ and the difference between the percentage of patients achieving response with rifaximin versus placebo (range, $7 \%$ to $10 \%$ ) is consistent with the findings of an analysis of clinical trials for eluxadoline (range, $4 \%$ to $13 \%$ ), another therapy used for the treatment of IBS-D. ${ }^{73}$ In a clinical study of IBS-D treatment with alosetron, differences between three alosetron dosing regimens and placebo ranged from $12.2 \%$ to $20.1 \%{ }^{83}$ Further, the placebo effect has been established in patients with IBS, as data from a randomized, controlled study of patients administered open-label placebo showed that patients achieved a significant improvement in IBS symptoms and symptom severity compared with no treatment ( $p=0.002$ and 0.03 , respectively). ${ }^{84}$ The mechanism behind the placebo effect in IBS remains to be elucidated but may involve neurological and psychological aspects, including patient expectations for symptom relief and conditioning, based on previous experiences with therapy, as well as the gut-brain axis. ${ }^{6,85}$

Rifaximin exhibits a favorable benefit-to-risk profile and is also administered as a short-course therapy for IBS-D. Given the well-known safety concerns regarding the effects of systemic antibiotics on the gut microbiota, health care providers may be concerned about the potential negative effect of nonsystemic rifaximin on the gut microbiota of patients with IBS-D. However, along with its favorable safety and tolerability profile, rifaximin has no apparent detrimental effects on gut microbiota and has not been associated with the emergence of clinically relevant bacterial antibiotic resistance in preclinical and clinical studies. ${ }^{86-89}$ Treatment with rifaximin $550 \mathrm{mg}$ tid for 2 weeks did not alter the overall composition of the gut microbiota in patients with nonconstipation IBS 4 weeks after the treatment ended. ${ }^{87}$ Further, repeat rifaximin treatment did not alter the composition of the gut microbiota in patients with IBS-D. ${ }^{87}$ Greater diversity in the gut microbiota was observed in patients with nonconstipation IBS after treatment with rifaximin, which steadily increased for up to 6 weeks after treatment; however, the increase from baseline in gut microbiota diversity did not achieve the level observed in the samples obtained from healthy individuals. ${ }^{87}$ Similarly, patients with IBS-D receiving up to three 2-week courses of treatment with rifaximin in a randomized, double-blind, placebo-controlled trial experienced modest, transient changes in the relative abundance of multiple taxa of the fecal microbiota, including Peptostreptococcaceae and Clostridiaceae. ${ }^{90}$ Observed changes were generally reversed by the end of the study (46 weeks). ${ }^{90}$ Gut microbiota changes that are most relevant to explaining the clinical effectiveness of rifaximin in improving symptoms of IBS-D may be too subtle for current DNA-based methods or analytics to detect. The resistance of staphylococcal isolates to rifampicin was not observed after a 10 -day course with rifaximin in rats; ${ }^{86}$ similarly, in patients with IBS-D receiving up to three courses of a 2-week treatment with rifaximin in the repeat treatment study, skin swabs from multiple locations and stool samples showed no evidence of resistance of staphylococcal isolates to rifaximin, rifampin, or other clinically relevant antibiotics. ${ }^{88,89}$

\section{Conclusion}

IBS is a chronic, common GI disorder, and both long-term and short-course therapies are considered part of an overall management strategy. Modulation of the gut microbiota with agents (eg, antibiotics and probiotics) thought to correct gut dysbiosis that occurs in patients with IBS is one approach. Data demonstrate that short-course (ie, 2-week) therapy with the nonsystemic antibiotic rifaximin is safe and efficacious for the treatment of IBS-D. Unless there is a contraindication to using a 2-week course of rifaximin, the literature suggests that it would be a reasonable first-line treatment choice for IBS-D, given the response rate and the durability of response, as well as its benefit-to-risk profile and lack of associated clinically significant bacterial antibiotic resistance.

\section{Acknowledgments}

Technical editorial assistance was provided, under the direction of the author, by Mary Beth Moncrief and Sophie Bolick (Synchrony Medical Communications, LLC, West Chester, 
PA, USA). Funding for this study was provided by Salix Pharmaceuticals, Bridgewater, NJ, USA.

\section{Author contributions}

Chang contributed toward data analysis, drafting and revising the paper and agrees to be accountable for all aspects of the work.

\section{Disclosure}

The author has served as an advisory board member of Salix Pharmaceuticals. The author reports no other conflicts of interest in this work.

\section{References}

1. Lacy BE, Mearin F, Chang L, et al. Bowel disorders. Gastroenterology. 2016;150(6):1393-1407.

2. Lovell RM, Ford AC. Global prevalence of and risk factors for irritable bowel syndrome: a meta-analysis. Clin Gastroenterol Hepatol. 2012;10(7):712-721.

3. Buono JL, Carson RT, Flores NM. Health-related quality of life, work productivity, and indirect costs among patients with irritable bowel syndrome with diarrhea. Health Qual Life Outcomes. 2017;15(1):35.

4. Enck P, Aziz Q, Barbara G, et al. Irritable bowel syndrome. Nat Rev Dis Primers. 2016;2:16014.

5. Liebregts T, Adam B, Bredack C, et al. Immune activation in patients with irritable bowel syndrome. Gastroenterology. 2007;132(3):913-920.

6. Koloski NA, Jones M, Kalantar J, Weltman M, Zaguirre J, Talley NJ. The brain-gut pathway in functional gastrointestinal disorders is bidirectional: a 12-year prospective population-based study. Gut. 2012;61(9):1284-1290.

7. Liu HN, Wu H, Chen YZ, Chen YJ, Shen XZ, Liu TT. Altered molecular signature of intestinal microbiota in irritable bowel syndrome patients compared with healthy controls: a systematic review and meta-analysis. Dig Liver Dis. 2017;49(4):331-337.

8. Hungin AP, Chang L, Locke GR, Dennis EH, Barghout V. Irritable bowel syndrome in the United States: prevalence, symptom patterns and impact. Aliment Pharmacol Ther. 2005;21(11):1365-1375.

9. Ford AC, Moayyedi P, Lacy BE, et al. American College of Gastroenterology monograph on the management of irritable bowel syndrome and chronic idiopathic constipation. Am J Gastroenterol. 2014;109(Suppl 1):S2-S26.

10. Carroll IM, Chang YH, Park J, Sartor RB, Ringel Y. Luminal and mucosal-associated intestinal microbiota in patients with diarrheapredominant irritable bowel syndrome. Gut Pathog. 2010;2(1):19.

11. Carroll IM, Ringel-Kulka T, Keku TO, et al. Molecular analysis of the luminal- and mucosal-associated intestinal microbiota in diarrheapredominant irritable bowel syndrome. Am J Physiol Gastrointest Liver Physiol. 2011;301(5):G799-G807.

12. Carroll IM, Ringel-Kulka T, Siddle JP, Ringel Y. Alterations in composition and diversity of the intestinal microbiota in patients with diarrhea-predominant irritable bowel syndrome. Neurogastroenterol Motil. 2012;24(6):521-530.

13. Durbán A, Abellán JJ, Jiménez-Hernández N, et al. Instability of the faecal microbiota in diarrhoea-predominant irritable bowel syndrome. FEMS Microbiol Ecol. 2013;86(3):581-589.

14. Parkes GC, Rayment NB, Hudspith BN, et al. Distinct microbial populations exist in the mucosa-associated microbiota of sub-groups of irritable bowel syndrome. Neurogastroenterol Motil. 2012;24(1):31-39.

15. Mätto J, Maunuksela L, Kajander K, et al. Composition and temporal stability of gastrointestinal microbiota in irritable bowel syndrome-a longitudinal study in IBS and control subjects. FEMS Immunol Med Microbiol. 2005;43(2):213-222.
16. Maukonen J, Satokari R, Mättö J, Soderlund H, Mattila-Sandholm T, Saarela M. Prevalence and temporal stability of selected clostridial groups in irritable bowel syndrome in relation to predominant faecal bacteria. J Med Microbiol. 2006;55(Pt 5):625-633.

17. Kassinen A, Krogius-Kurikka L, Mäkivuokko H, et al. The fecal microbiota of irritable bowel syndrome patients differs significantly from that of healthy subjects. Gastroenterology. 2007;133(1):24-33.

18. Tap J, Derrien M, Tornblom H, et al. Identification of an intestinal microbiota signature associated with severity of irritable bowel syndrome. Gastroenterology. 2017;152(1):111-123.e118.

19. Chang C, Lin H. Dysbiosis in gastrointestinal disorders. Best Pract Res Clin Gastroenterol. 2016;30(1):3-15.

20. Sachdev AH, Pimentel M. Gastrointestinal bacterial overgrowth: pathogenesis and clinical significance. Ther Adv Chronic Dis. 2013;4(5):223-231.

21. Pyleris E, Giamarellos-Bourboulis EJ, Tzivras D, Koussoulas V, Barbatzas C, Pimentel M. The prevalence of overgrowth by aerobic bacteria in the small intestine by small bowel culture: relationship with irritable bowel syndrome. Dig Dis Sci. 2012;57(5):1321-1329.

22. Su T, Lai S, Lee A, He X, Chen S. Meta-analysis: proton pump inhibitors moderately increase the risk of small intestinal bacterial overgrowth. $J$ Gastroenterol. 2018;53(1):27-36.

23. Giamarellos-Bourboulis EJ, Pyleris E, Barbatzas C, Pistiki A, Pimentel M. Small intestinal bacterial overgrowth is associated with irritable bowel syndrome and is independent of proton pump inhibitor usage. BMC Gastroenterol. 2016;16(1):67.

24. Rezaie A, Buresi M, Lembo A, et al. Hydrogen and methane-based breath testing in gastrointestinal disorders: the North American Consensus. Am J Gastroenterol. 2017;112(5):775-784.

25. Posserud I, Stotzer PO, Björnsson ES, Abrahamsson H, Simrén M. Small intestinal bacterial overgrowth in patients with irritable bowel syndrome. Gut. 2007;56(6):802-808.

26. Choung RS, Locke GR 3rd. Epidemiology of IBS. Gastroenterol Clin North Am. 2011;40(1):1-10.

27. Jacobs C, Coss Adame E, Attaluri A, Valestin J, Rao SS. Dysmotility and proton pump inhibitor use are independent risk factors for small intestinal bacterial and/or fungal overgrowth. Aliment Pharmacol Ther. 2013;37(11):1103-1111.

28. Rana SV, Malik A. Breath tests and irritable bowel syndrome. World $J$ Gastroenterol. 2014;20(24):7587-7601.

29. Shah ED, Basseri RJ, Chong K, Pimentel M. Abnormal breath testing in IBS: a meta-analysis. Dig Dis Sci. 2010;55(9):2441-2449.

30. Sachdeva S, Rawat AK, Reddy RS, Puri AS. Small intestinal bacterial overgrowth (SIBO) in irritable bowel syndrome: frequency and predictors. J Gastroenterol Hepatol. 2011;26(Suppl 3):135-138.

31. Ghoshal UC, Park H, Gwee KA. Bugs and irritable bowel syndrome: the good, the bad and the ugly. $J$ Gastroenterol Hepatol. 2010;25(2):244-251.

32. Park JH, Park DI, Kim HJ, et al. The relationship between smallintestinal bacterial overgrowth and intestinal permeability in patients with irritable bowel syndrome. Gut Liver. 2009;3(3):174-179.

33. Ghoshal UC, Ghoshal U. Small intestinal bacterial overgrowth and other intestinal disorders. Gastroenterol Clin North Am. 2017;46(1):103-120.

34. Pimentel M, Chow EJ, Lin HC. Eradication of small intestinal bacterial overgrowth reduces symptoms of irritable bowel syndrome. Am J Gastroenterol. 2000;95(12):3503-3506.

35. Pimentel M, Chow EJ, Lin HC. Normalization of lactulose breath testing correlates with symptom improvement in irritable bowel syndrome. A double-blind, randomized, placebo-controlled study. Am J Gastroenterol. 2003;98(2):412-419.

36. Low K, Hwang L, Hua J, Zhu A, Morales W, Pimentel M. A combination of rifaximin and neomycin is most effective in treating irritable bowel syndrome patients with methane on lactulose breath test. J Clin Gastroenterol. 2010;44(8):547-550.

37. Blondeau JM. What have we learned about antimicrobial use and the risks for Clostridium difficile-associated diarrhoea? J Antimicrob Chemother. 2009;63(2):238-242. 
38. Basseri RJ, Weitsman S, Barlow GM, Pimentel M. Antibiotics for the treatment of irritable bowel syndrome. Gastroenterol Hepatol (N Y). 2011;7(7):455-493.

39. Ward KM, Rounthwaite FJ. Neomycin ototoxicity. Ann Otol Rhinol Laryngol. 1978;87(2 Pt 1):211-215.

40. Yang J, Lee HR, Low K, Chatterjee S, Pimentel M. Rifaximin versus other antibiotics in the primary treatment and retreatment of bacterial overgrowth in IBS. Dig Dis Sci. 2008;53(1):169-174.

41. Zhang Y, Li L, Guo C, et al. Effects of probiotic type, dose and treatment duration on irritable bowel syndrome diagnosed by Rome III criteria: a meta-analysis. BMC Gastroenterol. 2016;16(1):62.

42. Li J, Zhu W, Liu W, Wu Y, Wu B. Rifaximin for irritable bowel syndrome: a meta-analysis of randomized placebo-controlled trials. Medicine (Baltimore). 2016;95(4):e2534.

43. Menees SB, Maneerattannaporn M, Kim HM, Chey WD. The efficacy and safety of rifaximin for the irritable bowel syndrome: a systematic review and meta-analysis. Am J Gastroenterol. 2012;107(1):28-35.

44. Didari T, Mozaffari S, Nikfar S, Abdollahi M. Effectiveness of probiotics in irritable bowel syndrome: updated systematic review with meta-analysis. World J Gastroenterol. 2015;21(10):3072-3084.

45. Ford AC, Quigley EM, Lacy BE, et al. Efficacy of prebiotics, probiotics, and synbiotics in irritable bowel syndrome and chronic idiopathic constipation: systematic review and meta-analysis. Am J Gastroenterol. 2014;109(10):1547-1561.

46. Moayyedi P, Ford AC, Talley NJ, et al. The efficacy of probiotics in the treatment of irritable bowel syndrome: a systematic review. Gut. 2010;59(3):325-332.

47. Leventogiannis K, Gkolfakis P, Spithakis G, et al. Effect of a preparation of four probiotics on symptoms of patients with irritable bowel syndrome: association with intestinal bacterial overgrowth. Probiotics Antimicrob Proteins. Epub 2018 Mar 5.

48. Xifaxan ${ }^{\circledR}$ (rifaximin) tablets, for oral use [package insert]. Bridgewater, NJ: Salix Pharmaceuticals; 2018.

49. Gatta L, Scarpignato C. Systematic review with meta-analysis: rifaximin is effective and safe for the treatment of small intestine bacterial overgrowth. Aliment Pharmacol Ther. 2017;45(5):604-616.

50. Kalambokis GN, Mouzaki A, Rodi M, et al. Rifaximin improves systemic hemodynamics and renal function in patients with alcohol-related cirrhosis and ascites. Clin Gastroenterol Hepatol. 2012;10(7):815-818.

51. Bajaj JS, Heuman DM, Sanyal AJ, et al. Modulation of the metabiome by rifaximin in patients with cirrhosis and minimal hepatic encephalopathy. PLoS One. 2013;8(4):e60042.

52. Pimentel M, Lembo A, Chey WD, et al. Rifaximin therapy for patients with irritable bowel syndrome without constipation. $N$ Engl J Med. 2011;364(1):22-32.

53. Lembo A, Pimentel M, Rao SS, et al. Repeat treatment with rifaximin is safe and effective in patients with diarrhea-predominant irritable bowel syndrome. Gastroenterology. 2016;151(6):1113-1121.

54. Pimentel M, Park S, Mirocha J, Kane SV, Kong Y. The effect of a nonabsorbed oral antibiotic (rifaximin) on the symptoms of the irritable bowel syndrome: a randomized trial. Ann Intern Med. 2006;145(8): $557-563$.

55. Lembo A, Zakko SF, Ferreira NL, et al. Rifaximin for the treatment of diarrhea-associated irritable bowel syndrome: short term treatment leading to long term sustained response. Gastroenterology. 2008;134(4 Suppl 1):A-545.

56. Sharara AI, Aoun E, Abdul-Baki H, Mounzer R, Sidani S, El Hajj I. A randomized double-blind placebo-controlled trial of rifaximin in patients with abdominal bloating and flatulence. Am J Gastroenterol. 2006;101(2):326-333.

57. Weinberg DS, Smalley W, Heidelbaugh JJ, Sultan S; American Gastroenterological Association. American Gastroenterological Association Institute Guideline on the pharmacological management of irritable bowel syndrome. Gastroenterology. 2014;147(5):1146-1148.

58. Kimer N, Krag A, Møller S, Bendtsen F, Gluud LL. Systematic review with meta-analysis: the effects of rifaximin in hepatic encephalopathy. Aliment Pharmacol Ther. 2014;40(2):123-132.
59. Festi D, Mazzella G, Orsini M, et al. Rifaximin in the treatment of chronic hepatic encephalopathy; results of a multicenter study of efficacy and safety. Curr Ther Res. 1993;54(5):598-609.

60. Miglio F, Valpiani D, Rossellini SR, Ferrieri A. Rifaximin, a non-absorbable rifamycin, for the treatment of hepatic encephalopathy. A doubleblind, randomised trial. Curr Med Res Opin. 1997;13(10):593-601.

61. Schoenfeld P, Pimentel M, Chang L, et al. Safety and tolerability of rifaximin for the treatment of irritable bowel syndrome without constipation: a pooled analysis of randomised, double-blind, placebo-controlled trials. Aliment Pharmacol Ther. 2014;39(10):1161-1168.

62. Shah E, Kim S, Chong K, Lembo A, Pimentel M. Evaluation of harm in the pharmacotherapy of irritable bowel syndrome. Am J Med. 2012;125(4):381-393.

63. Shah E, Pimentel M. Evaluating the functional net value of pharmacologic agents in treating irritable bowel syndrome. Aliment Pharmacol Ther. 2014;39(9):973-983.

64. Mullen KD, Sanyal AJ, Bass NM, et al. Rifaximin is safe and well tolerated for long-term maintenance of remission from overt hepatic encephalopathy. Clin Gastroenterol Hepatol. 2014;12(8):1390-1397.

65. Hayes P, Corish C, O'Mahony E, Quigley EM. A dietary survey of patients with irritable bowel syndrome. J Hum Nutr Diet. 2014;27(Suppl 2):36-47.

66. Muir JG, Gibson PR. The low FODMAP diet for treatment of irritable bowel syndrome and other gastrointestinal disorders. Gastroenterol Hepatol (N Y). 2013;9(7):450-452.

67. Shin J, McCombs JS, Sanchez RJ, Udall M, Deminski MC, Cheetham TC. Primary nonadherence to medications in an integrated healthcare setting. Am J Manag Care. 2012;18(8):426-434.

68. Cassell B, Gyawali CP, Kushnir VM, Gott BM, Nix BD, Sayuk GS. Beliefs about GI medications and adherence to pharmacotherapy in functional GI disorder outpatients. Am J Gastroenterol. 2015;110(10):1382-1387.

69. Spence MM, Karim FA, Lee EA, Hui RL, Gibbs NE. Risk of injury in older adults using gastrointestinal antispasmodic and anticholinergic medications. J Am Geriatr Soc. 2015;63(6):1197-1202.

70. VIBERZI ${ }^{\circledR}$ (eluxadoline) tablets, for oral use, CIV [package insert]. Irvine, CA: Allergan USA, Inc.; 2017.

71. Lotronex ${ }^{\circledR}$ (alosetron hydrochloride) tablets [package insert]. Roswell, GA: Sebela Pharmaceuticals Inc.; 2016.

72. Dove LS, Lembo A, Randall CW, et al. Eluxadoline benefits patients with irritable bowel syndrome with diarrhea in a phase 2 study. Gastroenterology. 2013;145(2):329-338.

73. Lembo AJ, Lacy BE, Zuckerman MJ, et al. Eluxadoline for irritable bowel syndrome with diarrhea. $N$ Engl J Med. 2016;374(3):242-253.

74. Chey WD, Chey WY, Heath AT, et al. Long-term safety and efficacy of alosetron in women with severe diarrhea-predominant irritable bowel syndrome. Am J Gastroenterol. 2004;99(11):2195-2203.

75. Lembo T, Wright RA, Bagby B, et al. Alosetron controls bowel urgency and provides global symptom improvement in women with diarrhea-predominant irritable bowel syndrome. Am J Gastroenterol. 2001;96(9):2662-2670.

76. Camilleri M, Northcutt AR, Kong S, Dukes GE, McSorley D, Mangel AW. Efficacy and safety of alosetron in women with irritable bowel syndrome: a randomised, placebo-controlled trial. Lancet. 2000;355(9209):1035-1040.

77. Tong K, Nicandro JP, Shringarpure R, Chuang E, Chang L. A 9-year evaluation of temporal trends in alosetron postmarketing safety under the risk management program. Therap Adv Gastroenterol. 2013;6(5):344-357.

78. US Food and Drug Administration. FDA drug safety communication: FDA warns about increased risk of serious pancreatitis with irritable bowel drug Viberzi (eluxadoline) in patients without a gallbladder [Press Release]. Silver Spring, MD: US Food and Drug Administration; Available from: https://www.fda.gov/Drugs/DrugSafety/ucm546154. htm. Published March 15, 2017. Accessed June 11, 2018.

79. Cash BD, Lacy BE, Schoenfeld PS, Dove LS, Covington PS. Safety of eluxadoline in patients with irritable bowel syndrome with diarrhea. Am J Gastroenterol. 2017;112(2):365-374. 
80. Whelan K. Editorial: The importance of systematic reviews and meta-analyses of probiotics and prebiotics. Am J Gastroenterol. 2014;109(10):1563-1565.

81. Islam SU. Clinical uses of probiotics. Medicine (Baltimore). 2016; 95(5):e2658.

82. Malnick S, Melzer E. Human microbiome: from the bathroom to the bedside. World J Gastrointest Pathophysiol. 2015;6(3):79-85.

83. Krause R, Ameen V, Gordon SH, et al. A randomized, double-blind, placebo-controlled study to assess efficacy and safety of $0.5 \mathrm{mg}$ and 1 $\mathrm{mg}$ alosetron in women with severe diarrhea-predominant IBS. Am J Gastroenterol. 2007;102(8):1709-1719.

84. Kaptchuk TJ, Friedlander E, Kelley JM, et al. Placebos without deception: a randomized controlled trial in irritable bowel syndrome. PLoS One. 2010;5(12):e15591.

85. Finniss DG, Kaptchuk TJ, Miller F, Benedetti F. Biological, clinical, and ethical advances of placebo effects. Lancet. 2010;375(9715): 686-695.
86. Kim MS, Morales W, Hani AA, et al. The effect of rifaximin on gut flora and Staphylococcus resistance. Dig Dis Sci. 2013;58(6):1676-1682.

87. Soldi S, Vasileiadis S, Uggeri F, et al. Modulation of the gut microbiota composition by rifaximin in non-constipated irritable bowel syndrome patients: a molecular approach. Clin Exp Gastroenterol. 2015;8:309-325.

88. DuPont HL, Wolf RA, Israel RJ, Pimentel M. Antimicrobial susceptibility of Staphylococcus isolates from the skin of patients with diarrhea-predominant irritable bowel syndrome treated with repeat courses of rifaximin. Antimicrob Agents Chemother. 2016;61(1):pii:e02165-e02116.

89. Pimentel M, Cash BD, Lembo A, Wolf RA, Israel RJ, Schoenfeld P. Repeat rifaximin for irritable bowel syndrome: no clinically significant changes in stool microbial antibiotic sensitivity. Dig Dis Sci. 2017;62(9):2455-2463.

90. Fodor A, Pimentel M, Chey WD, et al. Rifaximin is associated with modest, transient decreases in multiple taxa in the gut microbiota of patients with diarrhoea-predominant irritable bowel syndrome. Gut Microbes. Epub 2018 April 30.
Clinical and Experimental Gastroenterology

\section{Publish your work in this journal}

Clinical and Experimental Gastroenterology is an international, peerreviewed, open access, online journal publishing original research, reports, editorials, reviews and commentaries on all aspects of gastroenterology in the clinic and laboratory. This journal is included on PubMed. The manuscript management system is completely online 